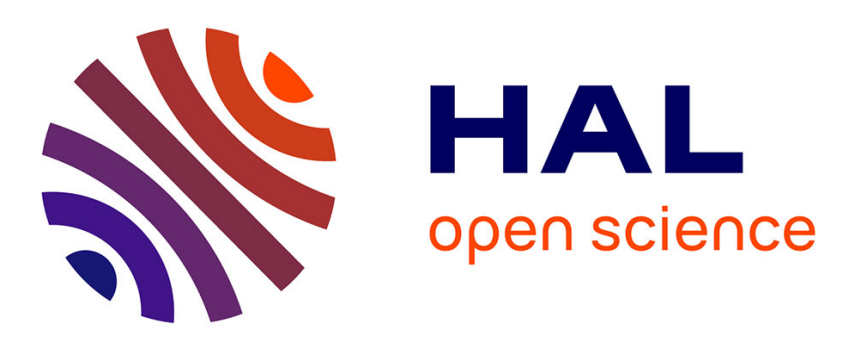

\title{
PCM compact model: Optimized methodology for model card extraction
}

Corentin Pigot, Fabien Gilibert, Marina Reyboz, Marc Bocquet, Jean-Michel Portal

\section{- To cite this version:}

Corentin Pigot, Fabien Gilibert, Marina Reyboz, Marc Bocquet, Jean-Michel Portal. PCM compact model: Optimized methodology for model card extraction. 2018 International Conference on Simulation of Semiconductor Processes and Devices (SISPAD), Sep 2018, Austin, United States. pp.190-193, 10.1109/SISPAD.2018.8551654 . cea-02188521

\section{HAL Id: cea-02188521 \\ https://hal-cea.archives-ouvertes.fr/cea-02188521}

Submitted on 22 Oct 2019

HAL is a multi-disciplinary open access archive for the deposit and dissemination of scientific research documents, whether they are published or not. The documents may come from teaching and research institutions in France or abroad, or from public or private research centers.
L'archive ouverte pluridisciplinaire HAL, est destinée au dépôt et à la diffusion de documents scientifiques de niveau recherche, publiés ou non, émanant des établissements d'enseignement et de recherche français ou étrangers, des laboratoires publics ou privés. 


\section{PCM compact model: Optimized methodology for model card extraction}

\author{
Corentin Pigot, Fabien Gilibert \\ STMicroelectronics \\ Crolles, France \\ corentin.pigot@st.com
}

\author{
Marina Reyboz \\ Univ. Grenobles Alpes, CEA-LETI \\ Grenoble, France \\ marina.reyboz@cea.fr
}

\author{
Marc Bocquet, Jean-Michel Portal \\ IM2NP, Aix-Marseille Université \\ Marseille, France \\ marc.bocquet@im2np.fr
}

\begin{abstract}
To achieve high yield on product embedding PCM memory, it is mandatory to provide to designers accurately calibrated PCM compact model. To achieve this goal, it is mandatory to develop standardized model card extraction methodology. In this paper, we present a PCM model card extraction flow based on a minimal set of static and dynamic measurements. Based on this measurement, characteristics are first obtained and model card parameters extracted without any loop back, i.e. each parameter is extracted only once on a given characteristic. After this extraction procedure, model card values are validated through a comparison with an extra characteristics SET-Low characteristic not used for the extraction.
\end{abstract}

Keywords—phase change random access memory; PCRAM; PCM; model extraction; compact model; resistive memory.

\section{INTRODUCTION}

In the resistive memory landscape, Phase Change Memory technology (PCM) is often seen as the most mature and well suited for embedded applications [1]. To successfully yield first products with embedded PCM, designers have to run extensive simulation campaign using PCM compact model. The main requirements for a compact model is to be fast, robust and accurate, so that designers are able to simulate correctly memory arrays. In this aim, we have already proposed a compact model of PCM (to appear in [2]), which is fully continuous, based on comprehensive rate equations and validated versus experimental data.

Compact model links technology development to circuit simulation by the mean of model card parameters. Thus any PCM technology evolution has to be taken into account by the compact model through model card extraction. In this context, the aim of this paper is to present an efficient model card extraction flow for our PCM compact model. The extraction methodology relies on a minimal set of static and dynamic measurements. Based on this measurement, characteristics are first obtained and model card parameters extracted without any loop back, i.e. each parameter is extracted only once on a given characteristic. The remainder of the paper is organized as follow: section II presents the specific the measurements that have to be performed together with the compact model main equations. Section III describes the model card extraction method, based upon validation on experiments, and finally section IV gives some concluding remarks.

\section{SPECIFIC ELECTRICAL CHARACTERIZATIONS AND THE DEVELOPPED COMPACT MODEL}

\section{A. Test Structure}

All measurements presented in the following are acquired on a wall-type PCM test structure [3] composed of a bipolar selector and a resistive element (1B1R). The PCM cell is a walltype structure, with a Ge-enriched GST material. A TEM crosssection as well as an equivalent schematics of the test structure is shown in Fig. 1.
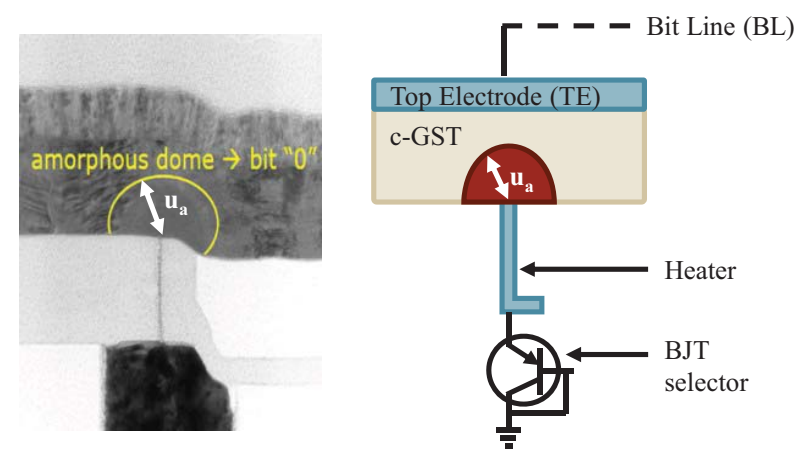

Fig. 1. TEM cross section of the test structure on the left hand side and equivalent schematics on the right hand side.

\section{B. Measurement setup}

The sketch of the transient measurements is presented in Fig. 2. A sequence of PROG pulses with increasing voltage and fixed time frame, as sketched Fig. 2.a) is called a staircase-up. This measurement is performed from both SET and RESET state, under several temperatures. It is used to plot programming current versus programming voltage (I-V), and read resistance against programming current (R-I) from both states. This measurement is also performed for several pulse widths, which allows to plot the SET Low characteristics that is the resistance versus current for several pulse widths. The last characterization (Fig. 2.b)) is performed by raising gradually the falling time of the programming pulse, identical otherwise. The read resistance as a function of the fall time (R-FT) is called Rampdown SET, and is used to study the quenching time. 


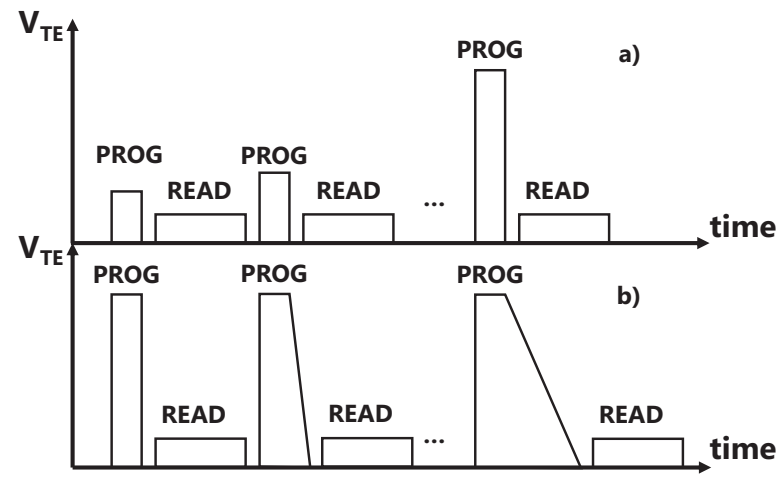

Fig. 2. Chronograms of the applied voltages. a) staircase-up measurement; b) quenching time measurement. The resistance during the reading pulse (READ) and the current during the programming pulse (PROG) are measured.

\section{Compact model equations and parameters}

Our fully continuous compact model [2] is based on rate equations of phase fractions. The device resistance is computed using phase resistances in series weighted by their respective phase fraction [4], as in equation (1):

$$
R_{P C M}=\left(F_{c}+F_{m}\right) R_{c}+\left(1-F_{m}-F_{c}\right) R_{a}+R_{\text {heater }}
$$

The model relies on two explicit state variables, which are $\mathrm{F}_{\mathrm{c}}$ and $\mathrm{F}_{\mathrm{m}}$, standing respectively for crystalline and melted fraction, the remaining part being considered as amorphous. Thus, equation (1) continuously links a semiconducting crystalline conduction [5] to a Poole-Frenkel type amorphous conduction [6]-[9], which are expressed in equations (2)-(4):

$$
\begin{gathered}
R_{c}=R_{c 0} \exp \left(\frac{E_{a c}}{k T}\right) \\
R_{a}=\left[\frac{A_{k P F}}{F_{c} \cdot u_{a, \max }} \exp \left(-\frac{\Phi_{P F}-\beta_{P F} \sqrt{F}}{k T}\right)\right]^{-1} \\
F=\frac{U}{u_{a, \max }\left(1-F_{c}-F_{m}\right)}
\end{gathered}
$$

The internal temperature is computed using equation (5) at the hottest spot of the GST using a first order differential equation [10], [11], and this approximation is corrected using several geometrical considerations, such as phase-dependent thermal resistances [12] shown in equation (6):

$$
\begin{gathered}
R_{t h} * C_{t h} \frac{\partial T}{\partial t}+T=R_{t h} * \frac{U^{2}}{R_{P C M}}+T_{a m b} \\
R_{t h}=R_{t h c}\left(F_{c}+F_{m}\right)+R_{t h a}\left(1-F_{m}-F_{c}\right)
\end{gathered}
$$

Melting transition (resp. crystallization) is computed as a solution of the first order differential equation (7) (resp. (8)):

$$
\begin{gathered}
\tau_{m} \frac{\partial F_{m}}{\partial t}+F_{m}=\left[1+\exp \left(\frac{T_{m}-T}{\sigma_{m}}\right)\right]^{-1} \\
\frac{\partial F_{c}}{\partial t}=\left(1-F_{m}-F_{c}\right) \cdot \frac{v_{g}\left(F_{c}, F_{m}\right)}{\tau_{s e t}(T)}
\end{gathered}
$$

The crystallization time $\tau_{\text {set }}$ follows a non-Arrhenius behavior [13]. Equation (9) is used to help control the retention time, and the fitting equation (10) is used to increase the growth speed for low amorphous fraction. This effect is introduced in the model to consider the temperature gradient inside the PCM cell neglected

\begin{tabular}{|c|c|c|}
\hline Symbol & Description & Value \\
\hline \multicolumn{3}{|c|}{ Conduction parameters } \\
\hline$A_{k P F}$ & Poole-Frenkel conduction prefactor & $3.10^{-12} \Omega^{-1} . \mathrm{m}$ \\
\hline$\beta_{P F}$ & Poole-Frenkel constant & $9 \mu \mathrm{eV} \cdot \mathrm{V}^{-0.5} \cdot \mathrm{m}^{0.5}$ \\
\hline$\Phi_{P F}$ & Poole-Frenkel Activation Energy & $0.15 \mathrm{eV}$ \\
\hline$u_{a \max }$ & Maximum size of the amorphous dome & $48 \mathrm{~nm}$ \\
\hline$R_{c o}$ & Crystalline resistance at $0 \mathrm{~K}$ & $3 \mathrm{k} \Omega$ \\
\hline$E_{a c}$ & $\begin{array}{l}\text { Activation energy of the crystalline } \\
\text { conduction }\end{array}$ & $0.04 \mathrm{eV}$ \\
\hline$R_{\text {heater }}$ & Resistance of the heater & $2.3 \mathrm{k} \Omega$ \\
\hline \multicolumn{3}{|c|}{ Thermal parameters } \\
\hline$C_{\text {th }}$ & Effective thermal capacitance & $10^{-16} \mathrm{~J}^{-\mathrm{K}^{-1}}$ \\
\hline$R_{\text {thc }}$ & Crystalline effective thermal resistance & $1.5 \mathrm{~K} . \mu \mathrm{W}^{-1}$ \\
\hline$R_{\text {tha }}$ & Amorphous effective thermal resistance & $5.8 \mathrm{~K} \cdot \mu \mathrm{W}^{-1}$ \\
\hline \multicolumn{3}{|c|}{ Melting parameters } \\
\hline$T_{m}$ & Melting temperature & $740 \mathrm{~K}$ \\
\hline$\sigma_{m}$ & Spread of the melting temperature & $67 \mathrm{~K}$ \\
\hline & Characteristic melting time & 1ns \\
\hline \multicolumn{3}{|c|}{ Crystallization parameters } \\
\hline$\tau_{O L T}$ & $\begin{array}{l}\text { Crystallization time prefactor for low } \\
\text { temperature }\end{array}$ & $2.10^{-39} \mathrm{~s}$ \\
\hline$E_{A L T}$ & Activation energy for low temperature & $3 \mathrm{eV}$ \\
\hline$\tau$ ТнНт & $\begin{array}{l}\text { Crystallization time prefactor for high } \\
\text { temperature }\end{array}$ & $300 \mathrm{~ns}$ \\
\hline$E_{A H T}$ & Activation energy for high temperature & $0.01 \mathrm{eV}$ \\
\hline$b$ & Fitting parameter & 10 \\
\hline
\end{tabular}
by our simple temperature calculation:

$$
\begin{gathered}
\tau_{\text {set }}(T)=\tau_{0 L T} \exp \left(\frac{E_{a L T}}{k T}\right)+\tau_{0 H T} \exp \left(\frac{E_{a H T}}{k T}\right) \\
v_{g}\left(F_{c}, F_{m}\right)=b \cdot\left(1-F_{m}-F_{c}\right) \cdot e^{1-b\left(1-F_{m}-F_{c}\right)}
\end{gathered}
$$

$\mathrm{U}$ is the voltage, $\mathrm{T}$ is the temperature and $\mathrm{k}$ is the Boltzmann constant. All other parameters are detailed in Table I.

TABLE I. PHYSICAL AND FITTING PARAMETERS

\section{MODEL CARD EXTRACTION FLOW}

The flow chart of the proposed extraction methodology is presented in table II. The first step of the extraction is the modeling of the crystalline and the melted conductions, through the fitting of the current-voltage characteristic for the SET state. The second and third steps are focusing on the I-V characteristics of the RESET state, in logarithmic scale for the fitting of the subthreshold conduction and the threshold switching. Crystalline and amorphous conductions are not intertwined and could be fitted in parallel. However, it is mandatory to fit them carefully prior to the other steps. Selfheating and melting parameters are extracted in step 4 on the resistance versus current characteristics from the SET state. It could also be extracted on the R-I characteristics from the RESET state, because both characteristics are superimposed in this regime. Then step 5 is performed to model crystallization dynamics, using the resistance vs. fall-time characteristics. The 
last step is used to verify the good consistency of the extraction flow, by checking whether SET Low is accurately modeled.

TABLE II. SUMMARY OF THE EXTRACTION STEPS

\begin{tabular}{|c|c|c|}
\hline Step & $\begin{array}{l}\text { Fitting target \& } \\
\text { extracted parameters }\end{array}$ & Experimental data \\
\hline 1 & $\begin{array}{c}\text { Crystalline \& melted } \\
\text { conduction } \\
\mathrm{R}_{\mathrm{c} 0}, \mathrm{E}_{\mathrm{ac}}, \mathrm{R}_{\text {heater }}\end{array}$ & $\begin{array}{l}\text { I-V from SET state in } \\
\text { temperature }\end{array}$ \\
\hline 2 & $\begin{array}{c}\text { Amorphous conduction } \\
A_{k P F}, u_{a, \max }, \Phi_{P F}\end{array}$ & $\begin{array}{l}\text { I-V from RESET state at } \\
\text { different temperatures }\end{array}$ \\
\hline 3 & $\begin{array}{l}\text { Threshold switching } \\
\mathrm{R}_{\text {tha }}\end{array}$ & $\begin{array}{l}\text { I-V from RESET state at } \\
\text { different temperatures }\end{array}$ \\
\hline 4 & $\begin{array}{l}\text { Self-heating \& melting } \\
R_{\text {thc }}, T_{m}, \sigma_{m}\end{array}$ & $\begin{array}{l}\text { R-I from SET state at } \\
\text { different temperatures }\end{array}$ \\
\hline 5 & $\begin{array}{c}\text { Crystallization } \\
\text { dynamics } \\
\tau_{0 H T}, E_{a H T}, b\end{array}$ & $\begin{array}{l}\mathrm{R}-\mathrm{FT} \text { at different } \\
\text { temperatures }\end{array}$ \\
\hline 6 & $\begin{array}{c}\text { SET Low crystallization } \\
\text { Verification }\end{array}$ & $\begin{array}{l}\text { R-I from RESET state at } \\
\text { different pulse width }\end{array}$ \\
\hline
\end{tabular}

The extraction strategy is sequential. Except from steps 1 and 2 that can be switched independently, all extractions steps depend on the previous one.

The current-voltage characteristics of the crystalline state is plotted in Fig. 3. The impact of the selector is not de-embedded, the voltage seeable in all the Fig. 3 and Fig. 4. On the contrary the strategy is to previously extract the transistor model card on a dedicated selector-only structure and simulated both models in series when extracting PCM's model card. The dynamic resistance at high voltage is the heater resistance $R_{\text {heater. The }}$ temperature impact is limited, so $\mathrm{E}_{\mathrm{ac}}$ is small. $\mathrm{R}_{\mathrm{c} 0}$ then models the low voltage resistance.

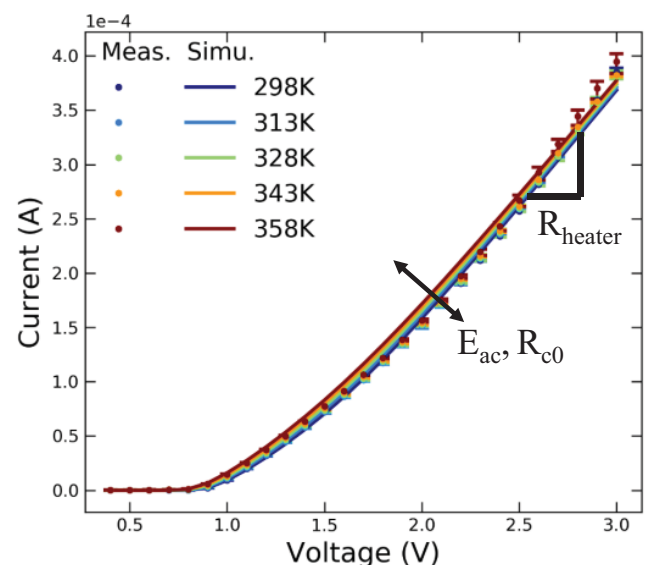

Fig. 3. Current versus voltage (I-V) during a staircase-up from SET state for several temperatures allowing the extraction of the crystalline conduction parameters $\left(\mathrm{R}_{\mathrm{c} 0}, \mathrm{E}_{\mathrm{ac}}, \mathrm{R}_{\text {heater }}\right)$.

Current versus voltage in amorphous state for several temperatures is presented in logarithmic scale in Fig 5. $\Phi_{\mathrm{PF}}$ tunes the spread of the curves, $\mathrm{u}_{\mathrm{a}, \max }$ the slope (the slope does not change in temperature), and $A_{\mathrm{kPF}}$ the level of the ambient curve. $\mathrm{R}_{\text {tha }}$ is then chosen so that the threshold switching is triggered at the correct voltage. The temperature dependence of the threshold switching is not well fitted above $328 \mathrm{~K}$, the model triggers earlier than the silicon. It seems that some thermal dissipation is not accurately taken into account.

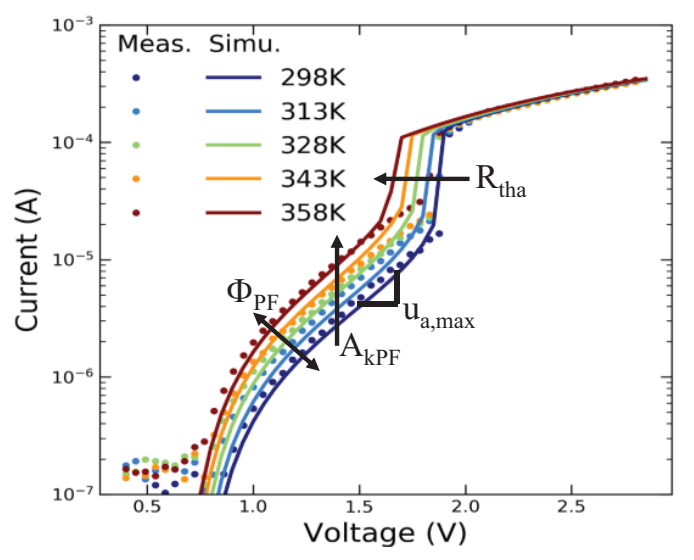

Fig. 4. Current versus voltage (I-V) during a staircase-up from RESET state for several temperatures allowing the extraction of the Poole-Frenkel parameters $\left(\mathrm{A}_{\mathrm{kPF}}, \mathrm{u}_{\mathrm{a}, \max }, \Phi_{\mathrm{PF}}\right)$. The threshold switching is fitted with the amorphous thermal resistance parameter $\mathrm{R}_{\text {tha }}$.

The high field part of the staircase-up measurement is shown in Fig. 5. It equates to a staircase-down measurement and exhibits melting characteristics. The model parameter accountable for the internal temperature at high field (in melted phase) is $R_{\text {thc }}$. Since all conduction-related parameters are previously extracted $\left(\mathrm{E}_{\mathrm{ac}}\right.$ and $\Phi_{\mathrm{PF}}$ have been extracted on the external temperature dependence), the spread between the curves is due to self-heating, so $\mathrm{R}_{\text {thc. }}$ We assume that the state achieved at the highest current (i.e. $350 \mu \mathrm{A}$ ) is fully amorphous, whereas the state in which the cell is programmed after a $150 \mu \mathrm{A}$ long-square-pulse is perfect crystal. This may have to change in the future, if over-programming is taken into account. The couple of parameters $\left(\mathrm{T}_{\mathrm{m}}, \sigma_{\mathrm{m}}\right)$ are then extracted in the transition, $\mathrm{T}_{\mathrm{m}}$ shifts the transition and $\sigma_{\mathrm{m}}$ steeps it.

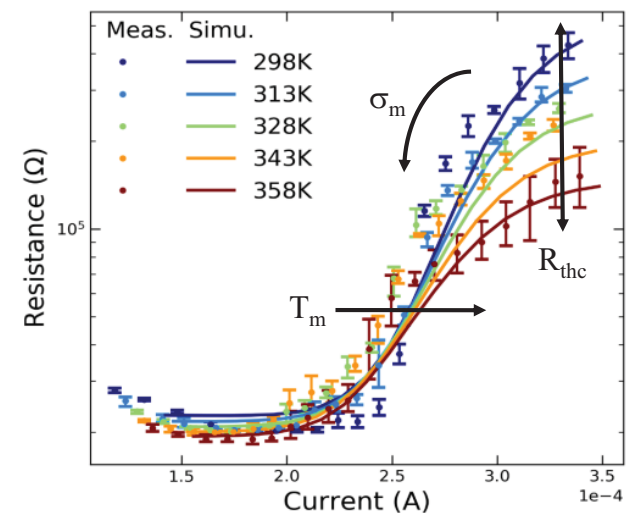

Fig. 5. Resistance versus current (R-I) during a staircase-up from SET state for several temperatures allowing the extraction of the thermal $\left(\mathrm{R}_{\mathrm{thc}}\right)$ and melting parameters $\left(\mathrm{T}_{\mathrm{m}}, \sigma_{\mathrm{m}}\right)$ 
The Rampdown SET characteristic is used to extract the crystallization parameters, i.e. $\tau_{0 \mathrm{HT}}, \mathrm{E}_{\mathrm{aHT}}$ and $\mathrm{b}$. It is presented in Fig. 6, where ther resistance versus fall time is plotted for several temperatures. $\tau_{0 \mathrm{HT}}$ fits the average time of crystallization, and $b$ the rapidity of the transition. The parameter $\mathrm{E}_{\mathrm{aHT}}$ is used to fit the faster transition at high temperature, but it does not seem to be the case so it is set to 0 , so that the ambient temperature does not affect the speed of the transition.

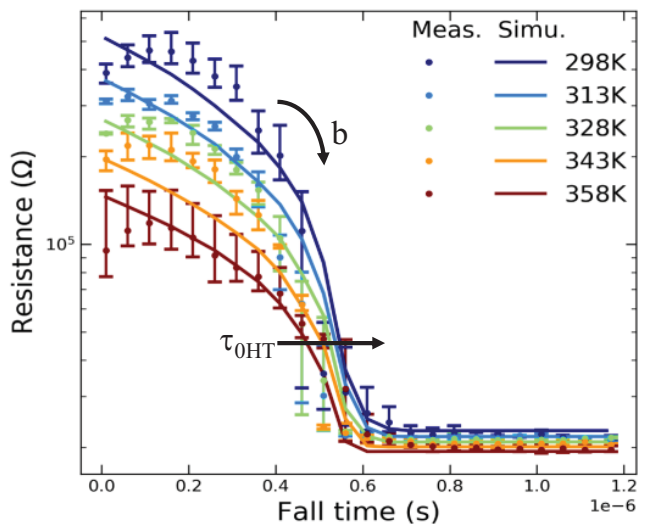

Fig. 6. Resistance versus fall time (R-FT) during a Rampdown SET for several temperatures allowing the extraction of the crystallization dynamics parameters $\left(\tau_{0 \mathrm{HT}}, \mathrm{E}_{\mathrm{aHT}}, \mathrm{b}\right)$.

Once all parameters are extracted, it is mandatory to verify that the model is also valid for SET low dynamics. The resistance versus current measured during a staircase-up with a variation of the pulse width is shown in Fig. 7. In the low current regime, the resistance level depends on the pulse width, shorter pulses allow less crystallization. The model is accurate from 600 ns.

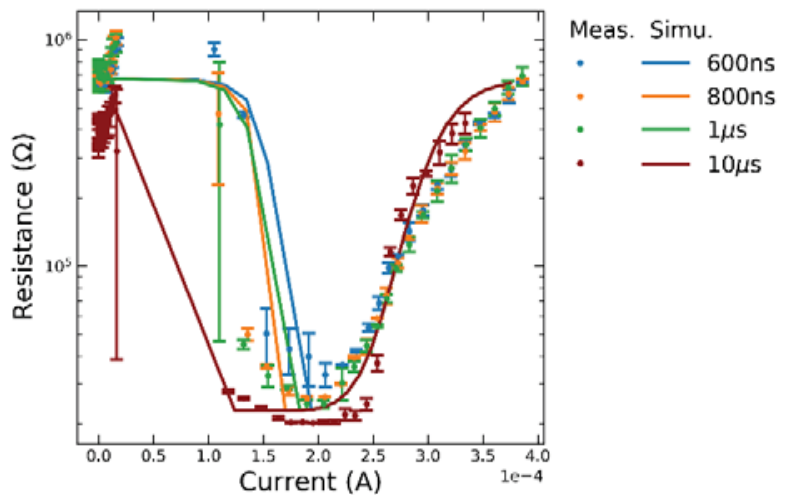

Fig. 7. SET Low: resistance versus current (R-I) during a staircase-up for several pulse widths validating of the accuracy of the extraction.

\section{CONCLUSION}

An optimized PCM model card extraction method has been successfully developed, based on a minimal set of fast acquired transient measurements. The proposed flow is logically constructed, so that each parameter is extracted only once, on one characteristic. The simulation versus measurements presents a good agreement for all characteristics where the parameters are extracted. Moreover, an extra characteristics have been accurately fitted with the same model card, which validates the accuracy of the extraction.

\section{REFERENCES}

[1] G. W. Burr et al., "Recent Progress in Phase-Change Memory Technology," IEEE J. Emerging Sel. Top. Circuits Syst., vol. 6, no. 2, pp. 146-162, Jun. 2016

[2] C. Pigot et al., "Comprehensive phase-change memory compact model for circuit simulation," IEEE Trans. Electron Devices, in press.

[3] R. Annunziata et al., "Phase Change Memory technology for embedded non volatile memory applications for $90 \mathrm{~nm}$ and beyond," in IEEE International Electron Devices Meeting, 2009, pp. 1-4.

[4] D. Ventrice, P. Fantini, A. Redaelli, A. Pirovano, A. Benvenuti, and F Pellizzer, "A Phase Change Memory Compact Model for Multilevel Applications,” IEEE Electron Device Lett., vol. 28, no. 11, pp. 973-975, Nov. 2007.

[5] J. A. Becker, C. B. Green, and G. L. Pearson, "Properties and Uses of Thermistors -Thermally Sensitive Resistors," Trans. Am. Inst. Electr. Eng., vol. 65, no. 11, pp. 711-725, 1946.

[6] Y. H. Shih et al., "Understanding amorphous states of phase-change memory using frenkel-poole model," in IEEE International Electron Devices Meeting - Technical Digest, 2009, vol. 3, pp. 753-756.

[7] R. M. Hill, "Poole-Frenkel conduction in amorphous solids," Philos. Mag., vol. 23, no. 181, pp. 59-86, 1971.

[8] C. Pigot, F. Gilibert, M. Reyboz, M. Bocquet, P. Zuliani, and J.-M. Portal, "Phase-change memory: A continuous multilevel compact model of subthreshold conduction and threshold switching,” Jpn. J. Appl. Phys., vol. 57, no. 4S, p. 04FE13, Apr. 2018.

[9] M. Le Gallo, A. Athmanathan, D. Krebs, and A. Sebastian, "Evidence for thermally assisted threshold switching behavior in nanoscale phasechange memory cells," J. Appl. Phys., vol. 119, no. 2, p. 025704, 2016.

[10] G. Marcolini et al., "Modeling the dynamic self-heating of PCM," in European Solid-State Device Research Conference, 2013, pp. 346-349.

[11] E. Covi, A. Kiouseloglou, A. Cabrini, and G. Torelli, "Compact model for phase change memory cells," in Conference on Ph.D. Research in Microelectronics and Electronics, 2014, pp. 1-4.

[12] K. Sonoda, A. Sakai, M. Moniwa, K. Ishikawa, O. Tsuchiya, and Y. Inoue, "A compact model of phase-change memory based on rate equations of crystallization and amorphization," IEEE Trans. Electron Devices, vol. 55, no. 7, pp. 1672-1681, 2008.

[13] N. Ciocchini, M. Cassinerio, D. Fugazza, and D. Ielmini, "Evidence for non-arrhenius kinetics of crystallization in phase change memory devices," IEEE Trans. Electron Devices, vol. 60, no. 11, pp. 3767-3774, 2013. 